\title{
A TRADUÇÃO JORNALÍSTICA DO IMPEACHMENT DE DILMA ROUSSEFF NA MÍDIA INTERNACIONAL
}

\author{
JOURNALISTIC TRANSLATION OF DILMA ROUSSEFF'S IMPEACHMENT IN \\ THE INTERNATIONAL MEDIA
}

\author{
(a) \\ Mariana Reis MENDES ${ }^{\mathrm{i}}$ \\ Mestranda em Estudos da Tradução (POSTRAD) \\ Universidade de Brasília \\ Distrito Federal, Brasília, Brasil. \\ maresia21@gmail.com
}

\begin{abstract}
Resumo: Na sociedade contemporânea, em que as barreiras geográficas e temporais são cada vez menores graças à popularização da internet, a tradução é fundamental, pois permite que pessoas de diferentes contextos culturais possam compartilhar informações em tempo real. A tradução é vista não apenas como o processo de busca por equivalências semânticas, mas como a resignificação de conteúdos em novos contextos. Este artigo propõe uma reflexão sobre a interface entre jornalismo e tradução, relacionando os pilares das duas profissões a busca pela objetividade e fidelidade, respectivamente - e a influência de diversos constrangimentos aos quais estão submetidas, a partir das Teorias do Jornalismo e dos Estudos da Tradução. O trabalho visa, por um viés sociolinguístico, identificar as diferentes abordagens do processo de impeachment da presidente do Brasil, Dilma Rousseff, em jornais online de abrangência mundial, a partir da comparação de notícias publicadas em inglês e português, e identificar as escolhas linguísticas que marcam estas abordagens. Para tanto, foram selecionadas matérias publicadas nestes idiomas nos jornais online Huffington Post e BBC na data da votação do processo de impeachment pela Câmara dos Deputados, 17 de abril de 2016. O trabalho apresenta um estudo quantitativo à luz da Linguística de Corpus, com auxílio de ferramentas de análise terminológica, que permitem a observação de diversos aspectos do texto que são relevantes para a pesquisa linguística. A análise permitiu observar que a tradução jornalística extrapola o campo semântico ao participar ativamente do jogo político através de escolhas semânticas marcadas pelas ideologias dos atores envolvidos no processo.
\end{abstract}

Palavras chave: Jornalismo. Tradução. Linguística de Corpus. Dilma Rousseff. Impeachment.

Abstract: In the contemporary society, where geographical and temporary barriers are getting smaller due to the popularization of internet, translation has an essential role, because it allows people from different cultural contexts to share real-time information. Translation is seen not only as the process of searching for semantic equivalences, but as resignification of contents in new contexts. This article purposes a reflection about the interface between journalism and translation, relating the pillars of these professions - search for objectivity and fidelity, respectively - and the influence of many constraints to each both professions are submitted to, through the Theories of Journalism and Translation Studies. This work aims to identify different approaches of the Brazilian president Dilma Rousseff's impeachment process in the international media, by a sociolinguistic point of view, through the comparison of news published in English and Portuguese. We try to identify the linguistic choices which mark these approaches. To do so, we selected news published on the selected languages on Huffington Post and BBC, at the date of the impeachment voting by the Brazilian Congress, April 17th, 2016. This article presents a qualitative study to the light of Corpus Linguistics, with the aid of terminological tools, which allows the observation of many different aspects of the texts which are relevant to the linguistic research. The analysis showed us that journalistic translation goes beyond the semantic field, as it participates actively of the political games through semantic choices marked by ideologies of actors involved in the process.

Keywords: Journalism. Translation. Corpus Linguistics. Dilma Rousseff. Impeachment. 


\section{Introdução}

A popularização da internet a partir dos anos 1970 permitiu que indivíduos localizados em espaços geográficos e ambientes socioculturais distintos compartilhassem diversos tipos de informações. Neste contexto, a tradução tem papel fundamental, ao permitir que conteúdos produzidos em um idioma fossem disseminados em outros, possibilitando o intercâmbio da informação, mas também de culturas e realidades diferentes. A tradução é vista, assim, não só como o processo de busca por equivalências semânticas, mas como a resignificação de conteúdos em contextos diferentes, nos quais servem a um propósito comunicativo.

Dentre os diversos tipos de conteúdos produzidos em uma determinada cultura, o jornalismo ganha destaque por divulgar fatos do cotidiano, fazendo com que se tenha a ideia do que é - ou se julga ser - relevante para esta sociedade. Neste sentido, a tradução de textos jornalísticos merece atenção especial, pois é através dela que diferentes contextos socioculturais se dão a conhecer uns aos outros.

Tendo em vista os aspectos políticos e ideológicos que permeiam o processo de construção da notícia, bem como o processo tradutório, este artigo pretende apresentar uma 84 reflexão sobre a interface entre jornalismo e tradução, através de um estudo de caso de abordagem sociolinguística. Para tanto, recorreremos, inicialmente, à pesquisa bibliográfica, na qual buscaremos fundamentação teórica sobre as Teorias do Jornalismo e dos Estudos da Tradução e sobre a interface entre as duas áreas. A seguir, a pesquisa bibliográfica terá como enfoque a abordagem Sociolinguística, as contribuições da Linguística de Corpus e da Terminologia para a pesquisa em tradução.

A seguir, será apresentado o corpus de referência, a saber, textos extraídos dos jornais online Huffington Post e BBC em suas versões em inglês e português na data da votação do processo de impeachment da presidenta Dilma Rousseff pela Câmara dos Deputados. Após apresentar o corpus e a metodologia utilizada para sua seleção, será apresentada a análise dos textos que compõem o corpus à luz das teorias que fundamentam este trabalho e dos resultados obtidos pelo programa AntConc. Finalmente, apresentamos as considerações finais desta pesquisa, bem como as prospecções para novos estudos sobre a relação entre jornalismo e tradução.

\section{A interface jornalismo e tradução}

O trabalho do jornalista é orientado pelo interesse público. A prática diária da profissão é direcionada, segundo Mauro Wolf (1999, p. 82), por critérios de noticiabilidade 
dos acontecimentos, ou seja, sua "aptidão para ser transformado em notícia", segundo o ponto de vista da estrutura dos veículos de informação e da cultura profissional dos jornalistas. Tais fatores atuam de forma complementar e permeiam todo o processo de produção da notícia, desde a própria escolha do fato a ser divulgado até a forma como este será abordado.

Segundo Wolf (1999, p. 87), tais valores se relacionam: “[...] às características substantivas das notícias; ao seu conteúdo; b. à disponibilidade do material e aos critérios relativos ao produto informativo; c. ao público; d. à concorrência" (WOLF, 1999, p. 87). No que diz respeito ao público, há que se considerar a clareza da linguagem, a atratividade da notícia para a audiência, entre outros aspectos. Vale ressaltar, no entanto, que estes valores não são absolutos e aplicáveis de forma estanque a todas as situações, mas variam de acordo com a empresa, o público alvo e o contexto sociocultural no qual estão inseridos.

Assim como o jornalismo, a tradução também se orienta pelo interesse público. Segundo Campos (2009, p. 45), embora até meados do século XX a prática tradutória fosse vista segundo os pilares da equivalência, precisão e fidelidade, a partir dos quais o tradutor seria capaz de transpor significados de um idioma para outro, a partir da "virada cultural", o tradutor passa a ser visto como construtor de significados, abandonando-se a ideia de que existe uma tradução perfeita e aceitando o pensamento de que há várias traduções possíveis, que carregam traços do tradutor e de seu tempo (PONTES JR; BATALHA, 2004, p. 37).

Sendo assim, da mesma forma que um fato só é traduzido em notícia se houver interesse do público sobre o assunto, um texto só é traduzido de um idioma a outro se houver necessidade ou interesse de leitores deste segundo idioma. Como bem lembram Paschoal e Barteto (2009, p. 8),

\footnotetext{
A tradução, então, não é apenas um processo que ocorre na mente do tradutor. Os leitores decidem aceitar ou rejeitar traduções. Diferentes tipos de leitor exigirão diferentes tipos de tradução. Nas palavras de Goethe: "Se você quer influenciar as massas, uma tradução simples é a melhor".
}

Neste contexto, o leitor não tem papel passivo, de mero receptor do conteúdo informacional que é oferecido, mas tem a escolha de aceitar o que ele quer ou precisa saber (NORD, 2005, p. 16). Pensando na intencionalidade do consumo do texto traduzido, a funcionalista Christiane Nord desenvolve uma teoria da tradução direcionada a um propósito comunicativo. Para ela, toda tradução pretende alcançar um propósito comunicativo em um público alvo, o que vai orientar o tradutor a fazer as escolhas adequadas para produzir um texto que se adeque às necessidades deste público (NORD, 2005, p. 17). 
O jornalismo e a tradução, ao traduzirem os fatos em notícia e estas notícias de um idioma a outro, respectivamente, introduzem o "outro", através de sua linguagem, permitindo a aproximação entre povos e culturas, o intercâmbio de informações, ideias, realidades e concepções de mundo diferentes. Deste modo, a tradução pode alterar ou consolidar ideias pré-estabelecidas, bem como construir uma identidade para uma cultura em outra, ou seja, assim como o jornalismo, cria representações culturais (PONTES JR E BATALHA, 2004, p. 28).

Apesar dos princípios da objetividade, para o jornalismo, e da fidelidade, para a tradução, na prática, a tradução de textos jornalísticos esbarra nestes princípios, uma vez que, o tradutor deste tipo de texto é muito mais que um mero transpositor de códigos linguísticos, mas tem a função de reinterpretar os acontecimentos de acordo com o contexto sociocultural e os interesses do público alvo (que diferem daquele do público para o qual o texto fonte foi originalmente produzido). Desta forma, a interface entre jornalismo e tradução

[...] tem como princípio questionar a existência de textos ditos neutros e imparciais, além de considerar a linguagem como manifestação cultural, ou seja, um ato vinculado a seu contexto de produção. Dessa maneira, a linguagem se constitui como produto de um meio social e também como processo formador de sentidos. Portanto, desconsiderá-la como uma manifestação cultural equivale ao que se poderia chamar de um primeiro paralelo entre tradução e jornalismo: a transcodificação isenta é, para a tradução, o que a neutralidade representa para o jornalismo (ZIPSER, 2002, p. 32, apud ZIPSER; POLCHLOPEK, 2006, p. 46)

As autoras adotam uma visão ampliada de texto, que se desloca não necessariamente em direção a um texto-fonte, mas a um fato gerador, ou seja, o evento que se tornou notícia (ZIPSER; POLCHLOPEK, 2006, p. 47). Assim, a tradução de notícias ultrapassa as barreiras meramente linguísticas, ao envolver parâmetros intra e extratextuais, fatores que se articulam de forma interdependente e dinâmica. Assim, a tradução adquire o sentido de representação cultural, e não mais de transcodificação isenta, ao envolver parâmetros culturais no processo de tradução das notícias (ZIPSER; POLCHLOPEK, 2006, p. 47).

Deste modo, ao observar o produto jornalístico (seja ele "original” ou traduzido), é possível identificar marcas dos fatores extratextuais, dentre eles, o receptor, que, de certa forma, condiciona outros fatores. Neste sentido, torna-se profícua a abordagem sociolinguística da tradução jornalística, principalmente com o auxílio das ferramentas terminológicas e da linguística de corpus, que nos permite extrair do texto elementos marcadores da diversidade de públicos ao qual o texto atende ou pretende atender. 


\section{As contribuições da Linguística de Corpus para o estudo da tradução jornalística}

Conforme Lacerda (2010, p. 128), a heterogeneidade linguística é um reflexo da heterogeneidade social. Desta forma, o uso da língua não será o mesmo em diferentes épocas, regiões, classes sociais, etc. O mesmo acontece com o jornalismo. Em cada sociedade ele irá se apresentar de uma forma, ou seja, apresentará nuances específicas e reveladoras do meio social em que se encontra, além de outros fatores, como o público ao qual se destina.

Ao considerar a língua em relação à estrutura social, adota-se, portanto, uma abordagem sociolinguística, já que "a sociolinguística estuda a língua em toda a sua variedade. Ela considera a variação linguística um fato que deve ser explicado [...]" (MCCLEARY, 2009, p. 6). Desta forma, a língua não é considerada como algo pronto e acabado, fechado a transformações e às influências do contexto e do meio social.

Embora muitos estudos sociolinguísticos se concentrem na língua em sua forma oral, a fala, também é possível aplicar a abordagem sociolinguística a textos escritos, pois, como foi dito anteriormente, a elaboração de um texto jornalístico, por exemplo, leva em consideração fatores extratextuais, como o ambiente organizacional, a cultura profissional do jornalista e o público ao qual se destina. Todas estas variáveis são variáveis sociais e, portanto, se combinadas a variáveis linguísticas, produzem uma pesquisa sociolinguística.

Um ramo ou subárea da linguística de extrema importância para a realização de um estudo dos produtos de tradução é a Linguística de Corpus. Para Stella Tagnin, um corpus é "uma coletânea de textos em formato eletrônico, compilada segundo critérios específicos, considerada representativa de uma língua (ou da parte que se pretende estudar), destinada à pesquisa" (apud RIBEIRO, 2004, p. 162). Desta forma, conforme lembram Kader e Richter (2013, p. 14), a Linguística de Corpus envolve a Linguística Computacional e a Estatística, uma vez que atua no manuseio de dados e seu tratamento de forma quantitativa.

Em estudos envolvendo a Linguística de Corpus, o uso de ferramentas tecnológicas é condição fundamental. Estas ferramentas permitem a realização de análises terminológicas, auxiliando o estudioso a "[...] compreender a natureza, o estatuto, a constituição e o funcionamento dos termos técnico-científicos" (KRIEGER; FINATTO, 2004, p. 70, apud KRIEGER, 2006, p. 200). Desta forma, para o linguista de corpus, a terminologia funciona como uma disciplina de apoio à tradução (KRIEGER, 2006, p. 198).

Dentre os inúmeros programas de análise terminológica disponíveis no mercado, para este artigo foi escolhido o Programa AntConc 3.2.1, criado pelo professor Laurence Anthony, da Universidade de Waseda, no Japão. Trata-se de um software gratuito, de livre acesso e 
compatível com os sistemas Windows, Mac OS $\mathrm{X}$ e Linux. O AntConc é um "concordanciador utilizado para listar as ocorrências de uma determinada palavra ou frase em uma quantidade definida de contextos [...]", que também pode ser utilizado para "[...] listar palavras em um texto ou corpus, extrair palavras-chave e colocados" (KADER; RICHTER, 2013, p. 13-14).

Assim, a partir dos dados obtidos pela análise automática do corpus selecionado para este trabalho, este trabalho pretende, a partir da análise terminológica, à luz da Linguística de Corpus, identificar marcas textuais da interpretação do jornalista sobre os fatos abordados, buscando relacionar as variáveis linguísticas às variáveis sociais que se inserem no contexto de produção do texto jornalístico e, neste caso, do texto jornalístico traduzido.

\section{Apresentação e análise do corpus}

O fato-gerador que causou a cobertura jornalística que será estudada neste trabalho é a votação do processo de impeachment da presidenta Dilma Rousseff pela Câmara dos Deputados, no dia 17 de abril de 2016, uma data em que os olhos da imprensa nacional e

88 internacional estavam voltados para o País e para os desdobramentos da votação em um cenário local e global.

Os veículos de comunicação dos quais seriam extraídas as reportagens para análise foram retirados da lista Digital: Top 50 Online News Entities (2015) (As 50 principais empresas de notícias online de 2015), elaborada pelo Pew Research Center, que fornece esse ranking com base no número total de visitantes e média de minutos por visitas em janeiro de 2015. Assim, foram selecionados dois veículos de comunicação - Huffington Post (o quarto do ranking geral) e $\mathrm{BBC}\left(15^{\circ}\right.$ do ranking $)$ - com base na disponibilidade de notícias em inglês e português de acesso gratuito.

Após a escolha do veículo, partiu-se à seleção das reportagens para análise, com base na ocorrência do fato (dia 17 de abril de 2016), associando as palavras "impeachment Dilma Roussef+site: [endereço do site de notícias]". Também foram consideradas matérias publicadas no dia 18 de abril, visto que a votação terminou na noite do dia 17 e algumas matérias sobre o caso só foram publicadas no dia seguinte. Após a pesquisa, foram selecionadas as matérias publicadas logo depois de terminada a votação do processo de impeachment em cada um dos sites de notícia, em suas versões em inglês (BBC Reino Unido e Huffington Post) e português (BBC Brasil e Brasil Post). 


\subsection{BBC e Huffington Post}

Os sites da BBC Reino Unido (www.bbc.co.uk) e BBC Brasil (www.bbc.com/portuguese) são vinculados à rede de televisão britânica British Broadcasting Corporation, fundada em 1922. O canal online do Reino Unido foi lançado em 1997, seguido pelo canal brasileiro, dois anos depois.

Segundo informações do próprio site da empresa, sua missão é "melhorar a vida das pessoas com programas e serviços que informem, eduquem e entretenham" e, a visão de "ser a organização mais criativa do mundo". Já os valores são os seguintes:

\footnotetext{
Confiança é a base da BBC: nós somos independentes, imparciais e honestos. O público está no coração de tudo o que fazemos.

Nós temos prazer em oferecer serviços de qualidade e valor.

Criatividade é a seiva da nossa organização.

Nós respeitamos uns aos outros e celebramos nossa diversidade para que todos possam dar o seu melhor.

Nós somos um na BBC: ótimas coisas acontecem quando trabalhamos juntos. (BBC, 2016)
}

No dia 23 de junho de 2016, foi realizada uma pesquisa sobre o público e outras informações a respeito dos sites da BBC, através da ferramenta de métrica Alexa, que pertence ao grupo Amazon.

Segundo a análise realizada, o site www.bbc.co.uk é o $108^{\circ}$ mais acessado do mundo, e ocupa o $6^{\circ}$ lugar no ranking do Reino Unido. Com relação ao perfil geral de usuários da internet, os visitantes da BBC UK são compostos por pessoas com pós-graduação, em sua maioria, com equilíbrio entre homens e mulheres, que acessam o site principalmente a partir de seu local de estudo. Os países que mais visitam o site, segundo a análise são: Reino Unido $(66,7 \%)$; Estados Unidos $(8,5 \%)$, Índia (2\%), China (1,3\%) e Canadá $(1,1 \%)$.

A mesma busca foi realizada para o site www.bbc.com/portuguese. No entanto, por se tratar de um subdomínio, o endereço analisado (automaticamente) pelo Alexa foi o www.bbc.com (BBC World). Este site ficou na $129^{\mathrm{a}}$ colocação do ranking mundial e $98^{\mathrm{a}}$ nos Estados Unidos. A distribuição geográfica dos visitantes foi a seguinte: 25,2\% dos Estados Unidos, 6,5\% da Índia, 4,1\% do Reino Unido, 3,2\% do Paquistão e outros 3,2\% do Canadá. Com relação ao perfil geral de usuários da internet, a audiência do www.bbc.com é composta principalmente por homens com pós-graduação, que acessam o site do trabalho.

O Huffington Post foi criado em maio de 2005 por Ariana Huffington e o ex-executivo da AOL, Kenneth Lerer. Além dos Estados Unidos, o Huffington Post tem edições no Reino 
Unido, Canadá, França, Espanha, Itália, Japão, Maghreb, Alemanha, Brasil e Coreia do Sul. O site é uma tentativa de resposta liberal ao Drudge Report, um site de notícias conservador que reúne manchetes de todo o mundo.

Uma das principais características do Huffington Post é que, inicialmente, o site trabalhou com a colaboração de blogueiros da área política e cultural, além de contribuições de celebridades, que trabalhavam sem receber pagamento, apenas em troca da exposição. Além disso, o Huffington Post se consolidou como um agregador de notícias.

Segundo o ranking do Alexa, o Huffington Post é o $161^{\circ}$ site mais visitado do mundo e o $43^{\circ}$ nos Estados Unidos. Em comparação à população geral da internet, os visitantes do site são compostos principalmente por mulheres com ensino superior, que acessam o sítio de casa, do trabalho ou da escola. A distribuição geográfica dos visitantes do site é a seguinte: 73,8\% dos Estados Unidos; 3,9\% da Índia; 2,5\% do Canadá, 2,1\% do Reino Unido e $1 \%$ da China.

Já o Brasil Post foi o décimo site vinculado ao Huffington Post a ter um endereço próprio, em 2014. A versão brasileira do site de notícias é vinculada à Editora Abril. Segundo o ranking do Alexa, o Brasil Post ocupa uma posição bastante tímida na colocação mundial $9024.838^{a}$ posição; $612^{a}$ no Brasil. Em comparação à população geral da internet, os usuários deste site são formados igualitariamente por homens e mulheres, sendo a maioria com curso de pós-graduação, que acessam o site de casa.

\subsection{Análise}

Para facilitar a análise dos textos publicados pelos sites de notícia em questão, organizaremos as informações levantadas através de pesquisa em tabelas. Em primeiro lugar, passaremos à análise manual, ou seja, sem o auxílio do programa AntConc. A Tabela 1 mostra os resultados encontrados nesta primeira etapa da pesquisa.

Quadro 1 - Análise manual de reportagens postadas

\begin{tabular}{|l|l|l|l|l|}
\hline & BBC UK & BBC Brasil & $\begin{array}{l}\text { Huffington } \\
\text { Post }\end{array}$ & Brasil Post \\
\hline Título & $\begin{array}{l}\text { "Brazil house votes for } \\
\text { Rousseff's impeachment } \\
- \text { The lower house of } \\
\text { congress in Brazil has } \\
\text { voted to go ahead with } \\
\text { impeachment" }\end{array}$ & $\begin{array}{l}\text { "Câmara aprova } \\
\text { continuidade do } \\
\text { impeachment de } \\
\text { Dilma Rousseff; } \\
\text { veja destaques" } \\
\text { president is } \\
\text { one step } \\
\text { closer to } \\
\text { impeachment }\end{array}$ & $\begin{array}{l}\text { Aprovado: } \\
\text { Câmara dos } \\
\text { Deputados } \\
\text { aprova } \\
\text { impeachment } \\
\text { de Dilma } \\
\text { house of } \\
\text { Congress } \\
\text { voted to }\end{array}$ & $\begin{array}{l}\text { Rousseff" } \\
\text { impeach }\end{array}$ \\
\hline
\end{tabular}




\begin{tabular}{|c|c|c|c|c|c|}
\hline & & & Rousseff" & \\
\hline \multicolumn{2}{|c|}{ Descrição da matéria } & Cobertura ao vivo. & $\begin{array}{l}\text { Cobertura ao } \\
\text { vivo. }\end{array}$ & $\begin{array}{l}\text { Texto } \\
\text { publicado ao } \\
\text { final da } \\
\text { votação. }\end{array}$ & $\begin{array}{l}\text { Texto } \\
\text { publicado ao } \\
\text { final da } \\
\text { votação. }\end{array}$ \\
\hline \multirow{2}{*}{\multicolumn{2}{|c|}{ Total de insercões }} & Assinado por editor. & $\begin{array}{l}\text { Sete repórteres e } \\
\text { correspondentes. }\end{array}$ & $\begin{array}{l}\text { Agência } \\
\text { Reuters com } \\
\text { informações } \\
\text { de repórteres } \\
\text { e edição. }\end{array}$ & $\begin{array}{l}\text { Assinado por } \\
\text { um repórter }\end{array}$ \\
\hline & & 98 & 131 & 1 & 1 \\
\hline \multirow{9}{*}{$\begin{array}{l}\text { Fotografias } \\
\text { e outras } \\
\text { imagens }\end{array}$} & $\begin{array}{l}\text { Movimentação } \\
\text { contrária }\end{array}$ & 9 & 20 & 0 & 17 \\
\hline & $\begin{array}{l}\text { Movimentação } \\
\text { a favor }\end{array}$ & 19 & 18 & 10 & 1 \\
\hline & $\begin{array}{l}\text { Movimentação } \\
\text { geral }\end{array}$ & 3 & 2 & 0 & 1 \\
\hline & Dilma & 2 & 1 & 0 & 0 \\
\hline & $\begin{array}{l}\text { Políticos } \\
\text { contrários }\end{array}$ & 0 & 5 & 0 & 0 \\
\hline & $\begin{array}{l}\text { Políticos a } \\
\text { favor }\end{array}$ & 0 & 3 & 0 & 0 \\
\hline & $\begin{array}{l}\text { Políticos em } \\
\text { geral }\end{array}$ & 2 & 2 & 0 & 0 \\
\hline & Outros & 18 & 10 & 0 & 0 \\
\hline & Total & 63 & 61 & 11 & 20 \\
\hline
\end{tabular}

(FONTE: a autora)

O primeiro item analisado nos textos foi o título. Em primeiro lugar, podemos observar a diferença de tamanho entre as publicações em inglês e em português. Enquanto o título das notícias brasileiras é mais sucinto (75 caracteres com espaços na BBC Brasil e 79 no Brasil Post), o tamanho dos textos em inglês é bem maior (124 caracteres com espaço na BBC e 108 no Huffington Post) o que leva a crer que o autor (ou editor) tenta explicar o assunto ao leitor estrangeiro (estratégias de explicação e explicitação), enquanto, nas edições em português, isto não seria necessário. Além disso, merece destaque o tratamento dado à notícia pelo Brasil Post, que apresenta o processo de impeachment como acabado, ao dizer "Impeachment Aprovado: Câmara dos Deputados aprova impeachment de Dilma Rousseff". Tal informação não é verdadeira, uma vez que, na ocasião da publicação, o processo de impeachment ainda estava em andamento, e a votação pela Câmara seria apenas um dos passos para que o mesmo acontecesse.

Outro fator que chama a atenção são as assinaturas. Percebe-se que as matérias em português estão assinadas, enquanto as matérias em inglês são feitas com base nos relatos dos repórteres locais (como no caso da BBC), ou via agência notícia (como no Huffington Post). No entanto, apenas a matéria da BBC UK pode ser considerada uma tradução (de um texto- 
fonte para um texto-meta; de um idioma para outro) do texto em português, já que a matéria do Huffington Post teve origem diferente daquela apresentada no Brasil Post.

No que diz respeito à cobertura fotográfica, observa-se que, tanto na reportagem da BBC UK quanto na do Huffington Post, foram priorizadas as imagens das manifestações favoráveis ao impeachment. Uma possível causa para esta preferência seria que, para os leitores estrangeiros, não há tanto interesse em conhecer "os dois lados da moeda", ou entender as minúcias do processo de impeachment, mas sim em saber o resultado final, quem "ganhou" e quem "perdeu". Já nas reportagens das versões brasileiras, observa-se um cenário diferente. Enquanto a notícia da BBC Brasil tentou equilibrar imagens das manifestações contrárias com as a favor (20 e 18 imagens, respectivamente), a notícia veiculada pelo Brasil Post priorizou as imagens relacionadas a atos contra o impeachment, o que destoa do tom escolhido para o título (que já deu o impeachment como concluído e a oposição ao governo como "vitoriosa").

Após concluída a análise manual, passaremos aos dados obtidos pelo AntConc. A lista de palavras-chave (keywords) foi obtida a partir da análise do programa, cruzando as palavras 92 presentes nos textos analisados a um corpus de referência. Assim, as palavras mais incomuns no corpus de referência são listadas por sua chavicidade e frequência (número de ocorrências), conforme consta na tabela abaixo:

Quadro 2 - Palavras-chave e tamanho do texto

\begin{tabular}{|l|l|l|l|l|}
\hline & BBC UK & BBC Brasil & Huffington Post & Brasil Post \\
\hline Keywords & Rousseff & impeachment & Rousseff & impeachment \\
& impeachment & processo & Brazil & Dilma \\
& vote & votos & impeachment & Rousseff \\
& Brazil & câmara & corruption & votação \\
& câmara \\
& Dilma & admissibilidade & Temer & presidente \\
& party & votação & Brazilian & senado \\
& Douse & Dilma & cast & impedimento \\
& favor & Janeiro & bancadas \\
& votes & senado & Rio & Michel \\
\hline Types & deputado & vote & 260 \\
\hline Tokens & 4.157 & 1.917 & 471 & 487 \\
\hline
\end{tabular}

$\mathrm{Na}$ tabela acima podemos verificar que algumas palavras compõem a lista de palavraschave dos quatro textos estudados. Impeachment e vote(s), voto e votação foram aquelas que aparecem nos quatro textos. Além delas, Dilma aparece na lista de três dos quatro textos, assim como Rousseff. O nome do vice-presidente, Michel Temer, aparece como palavra- 
chave em apenas dois dos textos (Temer na reportagem do Huffington Post e Michel na reportagem do Brasil Post).

Outro dado que pode ser observado a partir dos resultados fornecidos pelo AntConc é o número de word types (palavras únicas no texto, ou seja, sem contar as repetições) e word tokens (número total de palavras, incluindo as repetidas). Assim, pelos dados podemos perceber que a reportagem veiculada pela BBC Brasil apresenta um texto mais extenso (7.798 palavras) do que o texto do Brasil Post (487 palavras). Isto se deve ao tipo de relato adotado pela BBC, que fez uma cobertura ao vivo, com inserção de notas ao longo de todo o dia, num total de 130 inserções.

A tabela acima também indica a type-token ratio (TTR), ou seja, a taxa de variação lexical em cada um dos textos. O cálculo da TTR é feito através da divisão do número de types pelo número de tokens, multiplicado por cem. Segundo Williamson (2014, tradução nossa), uma TTR elevada indica uma grande quantidade de variação, enquanto uma TTR baixa indica pouca variação lexical. Assim, embora a reportagem veiculada pelo Brasil Post seja a menos extensa, é a que apresenta maior variação lexical com relação aos demais textos, visto que a TTR é de 53,4\%. A presença de um vocabulário mais denso pode ser justificada pelo tipo de público ao qual se destina o site (a maioria com curso de pós-graduação, ou seja, espera-se que dominem um repertório amplo).

O próximo passo para esta pesquisa foi a seleção de alguns termos para verificação de seus contextos, através da ferramenta Concordance do AntConc. Esta ferramenta apresenta o número total de ocorrências de uma determinada palavra em seu contexto, ou seja, na frase em que está inserida originalmente. Os resultados estão apresentados na Tabela 3, que segue abaixo. 
Quadro 3 - Análise da concordância de termos no AntConc

\begin{tabular}{|c|c|c|c|c|c|c|c|c|}
\hline & \multicolumn{2}{|c|}{ BBC UK } & \multicolumn{2}{|c|}{ BBC Brasil } & \multicolumn{2}{|c|}{$\begin{array}{c}\text { Huffington } \\
\text { Post }\end{array}$} & \multicolumn{2}{|c|}{ Brasil Post } \\
\hline \multirow[t]{4}{*}{ Impeachment } & TOTAL: & 85 & TOTAL: & 150 & TOTAL: & 6 & TOTAL: & 10 \\
\hline & Positiva: & 45 & Positiva: & 100 & Positiva: & 3 & Positiva: & 6 \\
\hline & Negativa: & 19 & Negativa: & 28 & Negativa: & 3 & Negativa: & 2 \\
\hline & Neutra: & 21 & Neutra: & 22 & Neutra: & 0 & Neutra: & 2 \\
\hline \multirow[t]{4}{*}{ Impedimento } & & & TOTAL: & 6 & & & TOTAL: & 3 \\
\hline & & & Positiva: & 2 & & & Positiva: & 2 \\
\hline & & & Negativa: & 4 & & & Negativa: & 0 \\
\hline & & & Neutra: & 0 & & & Neutra: & 1 \\
\hline \multirow[t]{4}{*}{ Golpe } & TOTAL: & 5 & TOTAL: & 12 & & & & \\
\hline & Positiva: & 0 & Positiva: & 7 & & & & \\
\hline & Negativa: & 4 & Negativa: & 5 & & & & \\
\hline & Neutra: & 1 & Neutra: & 0 & & & & \\
\hline \multirow[t]{4}{*}{ Coup } & TOTAL: & 12 & & & TOTAL: & 1 & & \\
\hline & Positiva: & 0 & & & Positiva: & 0 & & \\
\hline & Negativa: & 8 & & & Negativa: & 1 & & \\
\hline & Neutra: & 4 & & & Neutra: & 0 & & \\
\hline \multirow[t]{4}{*}{ Democracia } & & & TOTAL: & 16 & & & TOTAL: & 1 \\
\hline & & & Positiva: & 8 & & & Positiva: & 1 \\
\hline & & & Negativa: & 6 & & & Negativa: & 0 \\
\hline & & & Neutra: & 2 & & & Neutra: & 0 \\
\hline \multirow[t]{4}{*}{ Democracy } & TOTAL: & 8 & & & & & & \\
\hline & Positiva: & 4 & & & & & & \\
\hline & Negativa: & 3 & & & & & & \\
\hline & Neutra: & 1 & & & & & & \\
\hline \multirow[t]{4}{*}{ Presidenta } & & & TOTAL: & 1 & & & & \\
\hline & & & Positiva: & 1 & & & & \\
\hline & & & Negativa: & 0 & & & & \\
\hline & & & Neutra: & 0 & & & & \\
\hline \multirow{4}{*}{$\begin{array}{c}\text { Female } \\
\text { president }\end{array}$} & TOTAL: & 2 & & & TOTAL: & 1 & & \\
\hline & Positiva: & 2 & & & Positiva: & 1 & & \\
\hline & Negativa: & 0 & & & Negativa: & 0 & & \\
\hline & Neutra: & 0 & & & Neutra: & 0 & & \\
\hline \multirow[t]{4}{*}{ Presidente } & & & TOTAL: & 30 & & & TOTAL: & 4 \\
\hline & & & Positiva: & 13 & & & Positiva: & 0 \\
\hline & & & Negativa: & 13 & & & Negativa: & 4 \\
\hline & & & Neutra: & 4 & & & Neutra: & 0 \\
\hline \multirow[t]{4}{*}{ President } & TOTAL: & 40 & & & TOTAL: & 2 & & \\
\hline & Positiva: & 12 & & & Positiva: & 0 & & \\
\hline & Negativa: & 24 & & & Negativa: & 2 & & \\
\hline & Neutra: & 4 & & & Neutra: & 0 & & \\
\hline \multirow[t]{4}{*}{ Dilma } & TOTAL: & 21 & TOTAL: & 22 & & & TOTAL: & 6 \\
\hline & Positiva: & 5 & Positiva: & 6 & & & Positiva: & 2 \\
\hline & Negativa: & 16 & Negativa: & 12 & & & Negativa: & 3 \\
\hline & Neutra: & 5 & Neutra: & 4 & & & Neutra: & 2 \\
\hline \multirow[t]{4}{*}{ Rousseff } & TOTAL: & 36 & & & TOTAL: & 17 & & \\
\hline & Positiva: & 12 & & & Positiva: & 1 & & \\
\hline & Negativa: & 19 & & & Negativa: & 14 & & \\
\hline & Neutra: & 5 & & & Neutra: & 2 & & \\
\hline
\end{tabular}

(FONTE: a autora) 
Para esta etapa, foram escolhidos os seguintes termos: Impeachment/Impedimento; Golpe/Coup; Democracia/Democracy; Presidenta/Female president; Presidente/President; Dilma; e Rousseff. Vale ressaltar que, nesta análise, onde se pretende verificar a tendência da construção da imagem da presidenta Dilma Rousseff na mídia internacional, os termos presidente/president só foram considerados quando relacionados a Dilma. Já os termos Dilma e Rousseff só foram considerados quando mencionados separadamente, ou seja, apenas Dilma, sem a ocorrência de presidente/president ou Rousseff, no mesmo contexto; e apenas Rousseff, sem a ocorrência de presidente e Dilma no mesmo contexto.

Outra observação importante é que os termos acima elencados não foram escolhidos por fazer parte da lista de palavras-chave, mais por serem significativos no contexto político vivenciado pelo País, em que, de um lado, a base aliada de Dilma Rousseff associa o impeachment a um golpe e a um atentado à democracia e, de outro, a oposição considera o governo incapaz de se manter e o impeachment como sendo a garantia da democracia.

Uma primeira observação reveladora diz respeito ao tratamento de Dilma Rousseff por presidente (no masculino), na maioria das ocorrências, apesar da Lei $n^{\circ} 12.605$, de 3 de abril de 2012, que determina a obrigação da flexão de gêneros das profissões, quando possível. Além disso, muito antes da Lei, desde 1899, o termo é registrado pelo dicionário Houaiss, e designa "mulher que se elege para a presidência de um país" ou "mulher que exerce o cargo de presidente de uma instituição" (RODRIGUEZ, 2014).

No entanto, o termo presidenta só é utilizado uma vez, pela BBC Brasil, para se referir ao fato de que Dilma é a primeira mulher a ser eleita para o cargo no País. O mesmo ocorre com os textos da BBC UK (este com duas ocorrências) e do Huffington Post (apenas uma ocorrência), ao utilizar a expressão female president. O descaso à flexão de gênero pode ser apenas um preciosismo linguístico, mas pode também ser reflexo de uma instituição machista, que se recusa a utilizar o termo presidente em sua flexão feminina por questões ideológicas e políticas.

Outro aspecto interessante é que a BBC britânica, ao mencionar a presidenta pelo último nome, cita-a como Ms. Rousseff, ou seja, utilizando um pronome de tratamento para dar mais respeitabilidade ao referente. Já o Huffington Post não adota o mesmo padrão e, ao utilizar apenas o sobrenome da presidenta, o faz sem o uso do pronome de tratamento, assim como ocorre no Brasil. Embora, à primeira vista, a falta do pronome de tratamento possa parecer deselegante em comparação ao texto da BBC UK, a preferência por não utilizar o Ms pode ter sido uma tentativa de aproximar a narrativa jornalística do Huffington Post do 
modelo brasileiro, que também não utiliza pronomes de tratamento para se referir a Dilma Rousseff.

A ocorrência das expressões golpe ou coup se observa nos textos publicados na BBC UK, BBC Brasil e Huffington Post, sendo que o maior número de ocorrências se dá na reportagem da BBC Brasil. No entanto, vale notar que o termo sempre vem associado à fala de alguém (citação), entre aspas ou em discurso indireto. Assim, podemos perceber que, embora o Brasil Post ignore que a base governista intitule o processo de impeachment de golpe, os demais veículos mencionam esta informação, mesmo que de forma discreta, como o Huffington Post. Embora os sites ligados à BBC não defendam a posição da base aliada a Dilma, de que o impeachment seria um golpe, eles dão voz àqueles que defendem esta posição, ao contrário dos demais, o que parece mostrar uma abordagem mais imparcial, permitindo o contraponto de opiniões por parte do leitor, que, em sua maioria, é bastante esclarecido, conforme vimos anteriormente.

Os termos impeachment e impedimento aparecem, na maioria dos veículos estudados, com abordagem predominantemente positiva. Enquanto no texto publicado pela BBC UK os

96 contextos são majoritariamente positivos, na BBC Brasil há uma pequena discrepância, pois as ocorrências de impeachment são positivas, ao passo que as do termo impedimento são negativas. Já no Brasil Post, os dois termos aparecem em contextos positivos, enquanto no Huffington Post a concordância é mais frequente com palavras e expressões negativas.

De um modo geral, o termo democracia aparece de forma positiva em todos os textos, exceto pela reportagem do Huffington Post, no qual não há ocorrência desta. Já as referências a Dilma Rousseff são predominantemente negativas, haja vista estarem associadas, quase sistematicamente, a contextos relacionados ao impeachment.

\section{Considerações finais}

O texto jornalístico, como todo tipo de discurso, é permeado de sentidos e ideologias, desde o ambiente organizacional, aos jornalistas, leitores e o meio no qual ele será divulgado. Assim também acontece com a tradução, pois, nem o mais experiente e profissional dos tradutores será capaz de traduzir um texto-fonte para um texto-meta de forma totalmente objetiva e livre de intervenções do contexto no qual ele - o tradutor ou o texto-meta - e os leitores estão inseridos.

A tradução jornalística não se reduz, no entanto, à tradução interlingual, ou seja, entre idiomas. Trata-se, conforme defende Zipser e Polchlopek (2006), da tradução de um fato 
gerador em notícia, ou notícias, já que cada repórter, cada veículo terá sua própria visão e enquadramento dos fatos, assim como cada leitor fará a recepção de uma forma subjetiva.

A análise dos textos da BBC UK, BBC Brasil, Huffington Post e Brasil Post nos permitiu observar que mesmo veículos pertencentes a uma comunidade de interpretação determinada podem adotar abordagens diferentes, embora, muitas vezes, semelhantes em vários aspectos. Percebemos também que, embora alguns veículos adotem o conceito tradicional de tradução - entre idiomas, como a BBC UK fez com o texto da BBC Brasil isto não é uma regra, já que os textos do Huffington Post e Brasil Post não eram a tradução um do outro, e sim escritas diferentes do mesmo fato gerador, tendo sido, portanto, utilizada a tradução no contexto adotado por Zipser e Polchlopek (2006).

Embora a pesquisa não tenha sido exaustiva no que diz respeito à relação entre os aspectos sociais (composição do público de cada veículo, jornalistas envolvidos, etc.), e os aspectos linguísticos (observados à luz da Linguística de Corpus), foi possível perceber que dois fatores tiveram mais peso na elaboração dos textos jornalísticos: a escolaridade dos visitantes dos sites e a localização geográfica. Ao longo deste trabalho procuramos evidenciar algumas destas marcas linguísticas.

Mesmo que seja clara a interseção entre jornalismo e tradução, muito ainda há que se aprofundar neste tema, principalmente no que diz respeito à análise de como ocorre o processo de tradução em ambiente jornalístico. Por que alguns veículos optam por textos de agências de notícias a de enviados especiais? Por que não fazem a tradução de textos de correspondentes? E, mesmo nas agências de notícias, quem são os tradutores para os vários idiomas nos quais se publicam estas reportagens? Estes são apenas alguns dos questionamentos que apenas poderão ser respondidos com a continuidade da pesquisa acadêmica em tradução jornalística.

\section{REFERÊNCIAS BIBLIOGRÁFICAS}

BBC. History of the BBC. Disponível em: 〈http://www.bbc.co.uk/historyofthebbc>. Acesso em: 28 jun. 2016.

CAMPOS, Giovana Cordeiro. Estudos da tradução e análise do discurso: diálogos possíveis. Círculo fluminense de estudos filológicos e linguísticos. Rio de Janeiro: Cifefil, 2009. Disponível: < http://www.filologia.org.br/xiicnlf/12/05.pdf>. Acesso em: 10 nov 2015.

KADER, Cárla Callegaro Corrêa; RICHTER, Marcos Gustavo. Linguística de Corpus: possibilidades e avanços.Instrumento: Revista de Estudo e Pesquisa em Educação, Juiz de 
Fora, v. 15, n. 1, p.13-23, jan-jun 2013. Disponível em: $<$ https://instrumento.ufjf.emnuvens.com.br/revistainstrumento/article/view/2641>. Acesso em: 23 jun. 2016.

KRIEGER, Maria da Graça. Do ensino da terminologia para tradutores: diretrizes básicas. Cadernos de Tradução, Florianópolis, v. 1, n. 17, p.189-206, $1^{\text {o }}$ semestre de 2006. Disponível em: <https://periodicos.ufsc.br/index.php/traducao/article/view/6862>. Acesso em: 23 jun. 2016.

LACERDA, Patrícia F. A. da Cunha. Tradução e sociolinguística variacionista: a língua pode traduzir a sociedade?. Tradução \& Comunicação: Revista Brasileira de Tradutores, São Paulo, n. 20, p.127-142, $1^{\circ}$ semestre de 2010. Semestral. Disponível em: <http://pgsskroton.com.br/seer/index.php/traducom/article/view/1990>. Acesso em: 19 jun. 2016.

MCCLEARY, Leland. Sociolinguística. Florianópolis: Universidade Federal de Santa Catarina, 2009. Disponível em: <http://www.libras.ufsc.br/colecaoLetrasLibras/eixoFormacaoBasica/sociolinguistica/assets/5 47/TEXTO-BASE_Sociolinguistica.pdf>. Acesso em: 10 jun. 2016.

NORD, Christiane. Translating as a purposeful activity: a prospective approach. Tradterm, [s.1.], v. 11, n. 0, p.15-28, 18 abr. 2005. Universidade de Sao Paulo 98 Sistema Integrado de Bibliotecas - SIBiUSP. http://dx.doi.org/10.11606/issn.23179511.tradterm.2005.49673. Disponível em: <http://www.revistas.usp.br/tradterm/article/view/49673>. Acesso em: 19 jun. 2016.

PASCHOAL, Stéfano; BARTETO, Ruy. Estudos da tradução - uma breve reflexão sobre o universo da tradução literária segundo a obra translation/history/culture, de Lefevere e Bassnett. Revista Trama. Vol. 5, n. 9, 2009. Disponível em: <http://erevista.unioeste.br/index.php/trama/article/download/3849/3002>. Acesso em 4 nov. 2015.

PONTES JR, Geraldo Ramos; BATALHA, Maria Cristina. A tradução como prática da alteridade. Cadernos de Tradução. V. 1, n. 13. Florianópolis (SC), 2004. Disponível em: $<$ https://periodicos.ufsc.br/index.php/traducao/article/view/6230/5849>. Acesso em 04 nov. 2015.

RIBEIRO, Gabriela Castelo Branco. Tradução técnica, terminologia e linguística de corpus: a ferramenta Wordsmith Tools.Cadernos de Tradução, Florianópolis, v. 2, n. 14, p.159-174, $2^{\circ}$ semestre de 2004. Disponível em: $<$ https://periodicos.ufsc.br/index.php/traducao/article/view/6479/5974>. Acesso em: 23 jun. 2016.

RODRIGUEZ, Diogo Antonio. Falar "presidenta" é tão correto quanto "presidente". 2014. Disponível em: <http://www.cartacapital.com.br/politica/falar-201capresidenta201d-e-tao-correto-quanto-201ca-presidente201d-3220.html>. Acesso em: 22 jun. 2016.

WILLIAMSON, Graham. Type-token ratio of written language. 2014. Disponível em: <http://www.sltinfo.com/type-token-ratio/>. Acesso em: 22 jun. 2016. 
WOLF, Mauro. Teorias da Comunicação. 8. ed. Lisboa: Editora Presença, 1999. Tradução: Maria Jorge Vilar de Figueiredo.

ZIPSER, Meta Elisabeth; POLCHLOPEK, Silvana Ayub. A tradução de notícias: novos rumos para a pesquisa em tradução. Tradução \& Comunicação: Revista Brasileira de Tradutores, São Paulo, n. 15, p.45-53, set. 2006. Semestral. Disponível em: <http://sare.anhanguera.com/index.php/rtcom/article/view/125>. Acesso em: 19 jun. 2016.

\footnotetext{
${ }^{\text {i }}$ Mariana Reis Mendes - Bacharel em Jornalismo (2013) pela Universidade Federal do Tocantins. Disponível em: http://lattes.cnpq.br/1672672537730224. Acesso: novembro 2016.
}

RECEBIDO EM: 8 de outubro de 2016

ACEITO EM: 28 de outubro de 2016 